\title{
Indoor Particulate Matter Associated with Systemic Inflammation in COPD
}

\author{
S. Bose ${ }^{1}$, N. N. Hansel' ${ }^{1}$ E. S. Tonorezos ${ }^{2}$, D. L. Williams ${ }^{3}$, A. Bilderback ${ }^{1}$, P. N. Breysse ${ }^{3}$, \\ G. B. Diette ${ }^{1}$, Meredith C. McCormack ${ }^{*}$ \\ ${ }^{1}$ Johns Hopkins University Pulmonary and Critical Care Medicine, Baltimore, USA \\ ${ }^{2}$ Memorial Sloan-Kettering Cancer Center New York, New York, USA \\ ${ }^{3}$ Department of Environmental Health Sciences, Johns Hopkins Bloomberg School of Public Health, Baltimore, \\ USA \\ Email: *Mmccor16@jhmi.edu
}

Received 27 February 2015; accepted 25 May 2015; published 28 May 2015

Copyright (C) 2015 by authors and Scientific Research Publishing Inc.

This work is licensed under the Creative Commons Attribution International License (CC BY).

http://creativecommons.org/licenses/by/4.0/

c) (i) Open Access

\begin{abstract}
Chronic obstructive pulmonary disease (COPD) is a chronic disease characterized by progressive airflow obstruction, along with pulmonary and systemic inflammation. Outdoor PM has been associated with morbidity and mortality in COPD but less is known about effects of indoor air quality. In former smokers with COPD, we investigated in-home PM effects on pulmonary and systemic inflammation, symptoms, and lung function. Participants underwent in-home air monitoring for two weeks and simultaneous health assessments. Median (IQR) PM $_{2.5}$ was 9 (7) $\mu \mathrm{g} / \mathrm{m}^{3}$. Increased indoor $\mathrm{PM}_{2.5}$ was associated with increased white blood cells, predominantly neutrophils and lymphocytes, suggesting that even relatively low indoor $\mathrm{PM}_{2.5}$ may elicit a systemic inflammatory response in COPD.
\end{abstract}

\section{Keywords}

Particulate Matter, Indoor Pollution, Chronic Obstructive Pulmonary Disease (COPD)

\section{Introduction}

Chronic obstructive pulmonary disease (COPD) is a chronic respiratory disease characterized by progressive airflow obstruction with pulmonary and systemic inflammation that persists even after the inciting cause is removed [1] [2]. In industrialized nations, where it is the third leading cause of death [3] [4], cigarette smoking is the most common identifiable risk factor. However, other environmental exposures, such as outdoor air pollu-

${ }^{*}$ Corresponding author.

How to cite this paper: Bose, S., Hansel, N.N., Tonorezos, E.S., Williams, D.L., Bilderback, A., Breysse, P.N., Diette, G.B. and McCormack, M.C. (2015) Indoor Particulate Matter Associated with Systemic Inflammation in COPD. Journal of Environmental Protection, 6, 566-572. http://dx.doi.org/10.4236/jep.2015.65051 
tion, have also been linked to increases in morbidity and mortality. In particular, exposure to outdoor particulate matter (PM) has been independently associated with respiratory exacerbations, hospital admissions, and mortality in those with COPD [5]-[9].

Recently, there has been increasing recognition of the potential health implications of indoor air quality. Americans spend up to $90 \%$ of their time indoors [10], and specifically, older populations with COPD spend a greater portion of time indoors in their homes than their healthy counterparts [11]. As a result, the impact of indoor air upon these predominantly home dwellers may be much greater than our current knowledge of the effects of ambient pollution. Thus far, studies of indoor air quality and COPD have largely focused on the influence of biomass burning in developing countries, with isolated studies examining the health effects of indoor air quality on COPD in industrialized countries [12] [13]. Evidence that indoor pollutants within homes in the United States may be contributing to respiratory morbidity in individuals with COPD, even in the absence of smoking, is limited. Furthermore, the effects of indoor air pollution exposure upon pulmonary and systemic inflammation are not well established.

To address these gaps, we sought to determine the effect of short-term changes in in-home PM exposure on measures of pulmonary and systemic inflammation, symptoms, and lung function in a cohort of former smokers with COPD.

\section{Materials and Methods}

The study was approved by the Johns Hopkins University Department of Medicine Institutional Review Board and participants provided informed consent prior to enrollment. To be eligible for the study, participants were required to have physician-diagnosed COPD and to be former smokers with a greater than 10 pack year history of smoking. Air sampling was performed in the room where the participant spent the most time, typically the bedroom. $\mathrm{PM}_{2.5}$, particles less than $2.5 \mu \mathrm{m}$ in diameter and $\mathrm{PM}_{10}$, particles less than $10 \mu \mathrm{m}$ in diameter, concentrations were measured continuously in each participant's home during two consecutive weeks using $\mathrm{PM}_{10}$ and $\mathrm{PM}_{2.5}$ SKC PEM impactors loaded with 37-mm, 2.0- $\mu \mathrm{m}$ pore-size, Teflo ${ }^{\circledR}$ polytetrafluoroethylene membrane filters (Pall Corporation, Ann Arbor, MI). Airborne nicotine was measured using a passive sampler constructed and analyzed at Johns Hopkins Bloomberg School of Public Health Secondhand Smoke Exposure Assessment Core using previously described methods [14] [15]. Health outcomes assessed at baseline, 1, and 2 weeks included pre- and post-bronchodilator spirometry, performed according to American Thoracic Society/European Respiratory Society guidelines [16] using predicted values based on NHANES reference equations [17]. Standardized questionnaires included the St. George's Respiratory Questionnaire (SGRQ) (ranging from 0 to 100, higher scores indicate more limitation) [18] and the Breathlessness, Cough, and Sputum Scale (BCSS) (ranging from 0 to 12, higher scores indicate more severe disease [19]. Biologic markers included complete blood count (CBC) with differential, serum fibrinogen, and exhaled nitric oxide (eNO) [20]. Data were expressed as means and proportions, and exposure-outcome relationships examined by longitudinal data analysis using generalized estimating equations [21]. Multivariate models were adjusted for age, gender, education level (as a marker of socioeconomic status), and lung function. Analysis was conducted using Stata statistical software, version 12.0 (Stata Corp, College Station, TX), and statistical significance was reported at $\mathrm{p}<0.05$.

\section{Results}

Of the fifty participants, most were Caucasian (84\%), male (58\%), with an average [ \pm SD] age of $68 \pm 7$ years. All were former smokers with an average (SD) smoking history of $54 \pm 34$ pack years. The mean (SD) postbronchodilator $\mathrm{FEV}_{1}$ and $\mathrm{FEV}_{1} \%$ predicted were $1.7(0.8) \mathrm{L}$ and 61 (24), respectively. Participants were symptomatic with a baseline SGRQ total mean (SD) score of 32 (22) and an average (SD) BCSS score of 2.5 (2.4) (Table 1).

The median (IQR) in-home $\mathrm{PM}_{2.5}$ concentrations were 9 (7) $\mu \mathrm{g} / \mathrm{m}^{3}$ during the first 2 weeks, with median (IQR) values 10 (9) $\mu \mathrm{g} / \mathrm{m}^{3}$ during the first week and 9 (6) $\mu \mathrm{g} / \mathrm{m}^{3}$ during the second week. In-home $\mathrm{PM}_{2.5}$ concentrations did not vary greatly between consecutive weeks with a median (IQR) change of -1 (4) $\mu \mathrm{g} / \mathrm{m}^{3}$. The median (IQR) $\mathrm{PM}_{2.5-10}$ concentration was 5 (5) $\mu \mathrm{g} / \mathrm{m}^{3}$ and also varied little between weeks, with a median (IQR) change of $0(4) \mu \mathrm{g} / \mathrm{m}^{3}$.

The presence of environmental tobacco smoke was rare with $27 \%$ reporting any smoking indoors. This was supported by environmental monitoring which revealed $23 \%$ with undetectable air nicotine concentrations and 
Table 1. Participant characteristics*.

\begin{tabular}{|c|c|}
\hline Characteristic & $\mathbf{N}=\mathbf{5 0}$ \\
\hline Age (years) & $68(7)$ \\
\hline Gender (\% female) & 42 \\
\hline \multicolumn{2}{|l|}{ Race \% } \\
\hline Black & 14 \\
\hline White & 84 \\
\hline Other & 2 \\
\hline \multicolumn{2}{|l|}{ Education \% } \\
\hline$<$ High school & 8 \\
\hline High school & 39 \\
\hline Some college & 29 \\
\hline College graduate & 14 \\
\hline Graduate school & 10 \\
\hline Smoking history (pack years) & $54(34)$ \\
\hline \multicolumn{2}{|l|}{ Lung function (post-bronchodilator) } \\
\hline FEV1 (liters) & $1.7(0.8)$ \\
\hline FEV1 percent predicted & $61(24)$ \\
\hline FEV1/FVC & $0.57(0.12)$ \\
\hline \multicolumn{2}{|l|}{ Symptoms/quality of life } \\
\hline SGRQ & $32(22)$ \\
\hline BCSS (average of daily values) & $2.5(2.4)$ \\
\hline \multicolumn{2}{|l|}{ Biologic markers } \\
\hline WBC $\left(/ \mathrm{mm}^{3}\right)$ & $7103(1934)$ \\
\hline Neutrophils (/mm³) & $3771(1944)$ \\
\hline Lymphocytes $\left(/ \mathrm{mm}^{3}\right)$ & 1966 (652) \\
\hline Eosinophils $\left(/ \mathrm{mm}^{3}\right)$ & $223(155)$ \\
\hline Hemoglobin (g/dL) & $13.7(1.7)$ \\
\hline Platelets $\left(\mathrm{K} / \mathrm{mm}^{3}\right)$ & $243(86)$ \\
\hline Fibrinogen $^{+}(\mathrm{mg} / \mathrm{dL})$ & 451 (259) \\
\hline ENO (ppb) & $23(16)$ \\
\hline
\end{tabular}

*Expressed in mean (SD) unless specified.

$66 \%$ with low concentrations of $<0.1 \mu \mathrm{g} / \mathrm{m}^{3}$. Concentrations $<0.1 \mu \mathrm{g} / \mathrm{m}^{3}$ are low and represent an exposure consistent with less than half a cigarette per day [22].

Indoor $\mathrm{PM}_{2.5}$ was associated with increased serum white blood cell (WBC) count, with significant associations for both neutrophil and lymphocyte counts (Table 2), in both bivariate models and multivariate models. After adjustment for potential confounders, indoor $\mathrm{PM}_{2.5}$ concentrations were not associated with peripheral eosinophils, eNO, lung function, quality of life, or symptoms (Table 2). Similar analyses were conducted with coarse fraction of particles $\left(\mathrm{PM}_{2.5-10}\right)$ but no statistically significant relationships were found (not shown). 
Table 2. Association of indoor $\mathrm{PM}_{2.5}$ with lung function, symptoms, and biologic markers*.

\begin{tabular}{|c|c|c|c|c|}
\hline \multirow[t]{2}{*}{ Outcome } & \multicolumn{2}{|c|}{ Bivariate } & \multicolumn{2}{|c|}{ Multivariate" } \\
\hline & Point estimate & p-value & Point estimate & p-value \\
\hline \multicolumn{5}{|l|}{ Lung function } \\
\hline $\mathrm{FEV}_{1}$ percent predicted & 0.57 & 0.75 & 0.75 & 0.57 \\
\hline $\mathrm{FEV}_{1} / \mathrm{FVC}$ & -0.81 & 0.40 & -0.87 & 0.36 \\
\hline \multicolumn{5}{|l|}{ Symptoms/quality of life } \\
\hline $\mathrm{BCSS}^{+}$ & 0.22 & 0.06 & 0.04 & 0.26 \\
\hline $\mathrm{SGRQ}^{+}$ & 0.01 & 0.92 & 0.01 & 0.9 \\
\hline \multicolumn{5}{|l|}{ Biologic markers } \\
\hline WBC $\left(/ \mathrm{mm}^{3}\right)$ & 316 & $<0.01$ & 324 & $<0.01$ \\
\hline Neutrophils $\left(/ \mathrm{mm}^{3}\right)$ & 726 & 0.02 & 692 & 0.05 \\
\hline Lymphocytes (/mm³) & 304 & 0.01 & 293 & 0.03 \\
\hline Eosinophils $\left(/ \mathrm{mm}^{3}\right)$ & 0.26 & 0.05 & 0.14 & 0.26 \\
\hline Hemoglobin (g/dL) & 0.32 & 0.03 & 0.23 & 0.07 \\
\hline Platelets $\left(\mathrm{K} / \mathrm{mm}^{3}\right)$ & 3.43 & 0.56 & 4.86 & 0.39 \\
\hline Fibrinogen $^{+}(\mathrm{mg} / \mathrm{dL})$ & 0.01 & 0.93 & 0.18 & 0.66 \\
\hline $\mathrm{ENO}^{+}(\mathrm{ppb})$ & -0.17 & 0.09 & -0.13 & 0.23 \\
\hline
\end{tabular}

"Models are per change in log of $\mathrm{PM}_{2.5} ;{ }^{+}$Outcomes are log transformed; ${ }^{\text {"Models adjusted for age, gender, baseline FEV }}$, education. Lung function models adjusted for age, gender, education, and pack years.

\section{Discussion}

We found that increased indoor $\mathrm{PM}_{2.5}$ was associated with increased peripheral white blood cell count, predominantly neutrophils and lymphocytes in former smokers with COPD. It is noteworthy that this relationship between in-home PM and systemic inflammation was detected in homes with relatively low indoor PM concentrations where environmental tobacco smoke was not the major source of airborne PM.

The finding that exposure to relatively low concentrations of indoor PM can elicit a systemic inflammatory response in COPD is important as COPD is increasingly conceptualized as a chronic, systemic disease for which there are emerging, but nonetheless, limited treatment options. Systemic inflammation in COPD may contribute to disease morbidity and progression, including extra-pulmonary manifestations [23]. In fact, patients with COPD who have evidence of elevated inflammatory biomarkers, including serum WBC, may have increased frequency of exacerbations and increased all-cause mortality despite having similar lung function impairment [24]. It remains poorly understood why the inflammation in COPD persists, even after the inciting cause is removed (e.g. even after patients stop smoking). These results suggest air pollution, in particular indoor PM, may be one potentially modifiable factor that perpetuates the inflammatory response characteristic of COPD.

Our findings that exposure to fine particles results in a systemic inflammatory response are consistent with previous studies of outdoor air pollution [25] [26]. Furthermore, we demonstrated that these changes were specific to the $\mathrm{PM}_{2.5}$ fraction of particles, as coarse particles in this study were not associated with systemic markers of inflammation, adding to recent evidence that also suggests very limited effects of coarse PM upon inflammatory markers [27]. Ambient PM has been shown to mobilize the hemopoietic system into releasing leukocytes, including neutrophils and monocytes, into the peripheral circulation, suggesting an effect of PM on bone marrow [28]. Ex-vivo studies have suggested that this response is mediated by the release of pro-inflammatory cytokines (e.g. IL-1 $\beta$, IL-6, and GM-CSF) from alveolar macrophages, which phagocytize PM as it enters the lung [29]. Similar mechanisms may explain the leukocytic inflammation associated with increases in indoor PM. Particulate matter's potential effects on the hemopoietic system may also impact red blood cells, as demonstrated 
by studies that link ambient exposures to changes in hemoglobin in the blood [30]-[33]. Our findings may also support such a relationship, with a tendency towards a positive association between fine PM concentrations and hemoglobin, though this no longer reached statistical significance after multivariate analysis.

Current guidelines recognize indoor and outdoor air pollution as a harmful exposure but underscore the need for further evidence of health effects of indoor air pollution in COPD [34] [35]. One of the few studies examining indoor air quality and COPD was a cross-sectional study of 148 COPD patients in Scotland showing that higher $\mathrm{PM}_{2.5}$ concentrations were associated with worse quality of life [36]. Indoor PM concentrations in this study were heavily influenced by second-smoke (median $\mathrm{PM}_{2.5} 71 \mu \mathrm{g} / \mathrm{m}^{3}$ smoking homes vs $8 \mu \mathrm{g} / \mathrm{m}^{3}$ nonsmoking homes). In contrast, $\mathrm{PM}_{2.5}$ concentrations in the present study were consistent with those of nonsmoking homes. In a recent longitudinal study, indoor $\mathrm{PM}_{2.5}$ was associated with respiratory symptoms, rescue medication use and exacerbations [13]. The current study extends these findings and adds evidence that indoor PM is associated with systemic inflammation in COPD.

While our findings did not include evidence of an effect on symptoms or lung function, this may have been due to the modest sample size. Despite robust environmental monitoring and health outcome assessment at multiple time points, the relatively short duration of follow-up is a limitation. There may also be differential health effects related to PM sources, such as PM enriched with secondhand smoke versus PM from other sources, or unique effects in patients with different clinical phenotypes of COPD. Our sample was not large enough to conduct these types of stratified analyses but future, larger studies on indoor air quality and COPD are warranted.

The present study, together with the limited number of studies of indoor PM and COPD, sheds light on the potential impact of indoor air quality on vulnerable populations with COPD. The findings that even low concentrations of indoor PM are associated with a systemic inflammatory response addresses a gap in the evidence base and suggests that indoor PM exposure impacts health across a spectrum of concentrations and that there may not be a threshold indoor PM concentration below which can be considered "safe." More studies of health effects of indoor air quality in susceptible populations, including COPD, are needed to inform indoor air quality standards. Furthermore, studies that investigate the effect of improving air quality on COPD health outcomes are warranted as indoor air pollution may represent a modifiable environmental exposure and a novel therapeutic target.

\section{Conclusion}

Our study demonstrated that within homes of former smokers with COPD, levels of $\mathrm{PM}_{2.5}$, despite being low, were significantly associated with elevated markers of systemic inflammation, particularly neutrophils and lymphocytes. These findings suggest that environmental factors can impact patients with COPD even years after quitting smoking, and that interventions targeting indoor air quality have the potential to decrease morbidity in this population.

\section{References}

[1] Hogg, J.C. (2006) Why Does Airway Inflammation Persist after the Smoking Stops? Thorax, 61, 96-97. http://dx.doi.org/10.1136/thx.2005.049502

[2] Willemse, B.W., ten Hacken, N.H., Rutgers, B., Lesman-Leegte, I.G., Postma, D.S. and Timens, W. (2005) Effect of 1-Year Smoking Cessation on Airway Inflammation in COPD and Asymptomatic Smokers. European Respiratory Journal, 26, 835-845. http://dx.doi.org/10.1183/09031936.05.00108904

[3] (2012) Chronic Respiratory Diseases; Burden of COPD. World Health Organization. http://www.who.int/respiratory/copd/burden/en/index.html

[4] Miniño, A. (2011) Death in the United States, 2009. NCHS Data Brief, 64, 1-8.

[5] Dominici, F., Peng, R.D., Bell, M.L., Pham, L., McDermott, A., Zeger, S.L. and Samet, J.M. (2006) Fine Particulate Air Pollution and Hospital Admission for Cardiovascular and Respiratory Diseases. JAMA, 295, 1127-1134. http://dx.doi.org/10.1001/jama.295.10.1127

[6] Peacock, J.L., Anderson, H.R., Bremner, S.A., Marston, L., Seemungal, T.A., Strachan, D.P. and Wedzicha, J.A. (2011) Outdoor Air Pollution and Respiratory Health in Patients with COPD. Thorax, 66, 591-596. http://dx.doi.org/10.1136/thx.2010.155358

[7] Atkinson, R.W., Anderson, H.R., Sunyer, J., Ayres, J., Baccini, M., Vonk, J.M., Boumghar, A., Forastiere, F., Forsberg, B., Touloumi, G., Schwartz, J. and Katsouyanni, K. (2001) Acute Effects of Particulate Air Pollution on Respiratory Admissions: Results from APHEA 2 Project. Air Pollution and Health: A European Approach. American Journal of Respiratory and Critical Care Medicine, 164, 1860-1866. http://dx.doi.org/10.1164/ajrccm.164.10.2010138 
[8] Zhu, R., Chen, Y., Wu, S., Deng, F., Liu, Y. and Yao, W. (2013) The Relationship between Particulate Matter (PM $\left.{ }_{10}\right)$ and Hospitalizations and Mortality of Chronic Obstructive Pulmonary Disease: A Meta-Analysis. COPD, 10, 307-315. http://dx.doi.org/10.3109/15412555.2012.744962

[9] Ko, F.W. and Hui, D.S. (2012) Air Pollution and Chronic Obstructive Pulmonary Disease. Respirology, 17, $395-401$. http://dx.doi.org/10.1111/j.1440-1843.2011.02112.x

[10] Klepeis, N.E., Nelson, W.C., Ott, W.R., Robinson, J.P., Tsang, A.M., Switzer, P., Behar, J.V., Hern, S.C. and Engelmann, W.H. (2001) The National Human Activity Pattern Survey (NHAPS): A Resource for Assessing Exposure to Environmental Pollutants. Journal of Exposure Analysis and Environmental Epidemiology, 11, 231-252. http://dx.doi.org/10.1038/sj.jea.7500165

[11] Leech, J.A. and Smith-Doiron, M. (2006) Exposure Time and Place: Do COPD Patients Differ from the General Population? Journal of Exposure Science and Environmental Epidemiology, 16, 238-241.

[12] Osman, L.M., Douglas, J.G., Garden, C., Reglitz, K., Lyon, J., Gordon, S. and Ayres, J.G. (2007) Indoor Air Quality in Homes of Patients with Chronic Obstructive Pulmonary Disease. American Journal of Respiratory and Critical Care Medicine, 176, 465-472. http://dx.doi.org/10.1164/rccm.200605-589OC

[13] Hansel, N.N., McCormack, M.C., Belli, A.J., Matsui, E.C., Peng, R.D., Aloe, C., Paulin, L., Williams, D.L., Diette, G.B. and Breysse, P.N. (2013) In-Home Air Pollution Is Linked to Respiratory Morbidity in Former Smokers with Chronic Obstructive Pulmonary Disease. American Journal of Respiratory and Critical Care Medicine, 187, 10851090. http://dx.doi.org/10.1164/rccm.201211-1987OC

[14] Hammond, S.K. and Leaderer, B.P. (1987) A Diffusion Monitor to Measure Exposure to Passive Smoking. Environmental Science Technology, 21, 494-497. http://dx.doi.org/10.1021/es00159a012

[15] Apelberg, B.J., Hepp, L.M., Avila-Tang, E., Gundel, L., Hammond, S.K., Hovell, M.F., Hyland, A., Klepeis, N.E., Madsen, C.C., Navas-Acien, A., Repace, J., Samet, J.M. and Breysse, P.N. (2013) Environmental Monitoring of Secondhand Smoke Exposure. Tobacco Control, 22, 147-155. http://dx.doi.org/10.1136/tobaccocontrol-2011-050301

[16] Miller, M.R., Hankinson, J., Brusasco, V., Burgos, F., Casaburi, R., Coates, A., Crapo, R., Enright, P., van der Grinten, C.P., Gustafsson, P., Jensen, R., Johnson, D.C., MacIntyre, N., McKay, R., Navajas, D., Pedersen, O.F., Pellegrino, R., Viegi, G. and Wanger. J. (2005) Standardisation of Spirometry. European Respiratory Journal, 26, 319-338. http://dx.doi.org/10.1183/09031936.05.00034805

[17] Hankinson, J.L., Odencrantz, J.R. and Fedan, K.B. (1999) Spirometric Reference Values from a Sample of the General U.S. Population. American Journal of Respiratory and Critical Care Medicine, 159, 179-187. http://dx.doi.org/10.1164/ajrccm.159.1.9712108

[18] Jones, P.W., Quirk, F.H. and Baveystock, C.M. (1991) St George’s Respiratory Questionnaire. Respiratory Medicine, 85, 25-31.

[19] Leidy, N.K., Rennard, S.I., Schmier, J., Jones, M.K. and Goldman, M. (2003) The Breathlessness, Cough, and Sputum Scale: The Development of Empirically Based Guidelines for Interpretation. Chest, 124, 2182-2191. http://dx.doi.org/10.1378/chest.124.6.2182

[20] American Thoracic Society and European Respiratory Society (2005) ATS/ERS Recommendations for Standardized Procedures for the Online and Offline Measurement of Exhaled Lower Respiratory Nitric Oxide and Nasal Nitric Oxide. American Journal of Respiratory and Critical Care Medicine, 171, 912-930. http://dx.doi.org/10.1164/rccm.200406-710ST

[21] Zeger, S.L. and Liang, K.Y. (1986) Longitudinal Data Analysis for Discrete and Continuous Outcomes. Biometrics, 42, 121-130. http://dx.doi.org/10.2307/2531248

[22] Leaderer, B.P. and Hammond, S.K. (1991) Evaluation of Vapour-Phase Nicotine and Respirable Suspended Particle Mass as Markers for Environmental Tobacco Smoke. Environmental Science Technology, 25, 770-777.

[23] Barnes, P.J. and Celli, B.R. (2009) Systemic Manifestations and Comorbidities of COPD. European Respiratory Journal, 33, 1165-1185. http://dx.doi.org/10.1183/09031936.00128008

[24] Agusti, A.G.N., Noguera, A., Sauleda, J., Sala, E., Pons, J. and Busquets, X. (2003) Systemic Effects of Chronic Obstructive Pulmonary Disease. European Respiratory Journal, 21, 347-360. http://dx.doi.org/10.1183/09031936.03.00405703

[25] Hajat, A., Allison, M., Diez-Roux, A.V., Jenny, N.S., Jorgensen, N.W., Szpiro, A.A., Vedal, S. and Kaufman, J.D. (2015) Long-Term Exposure to Air Pollution and Markers of Inflammation, Coagulation, and Endothelial Activation: A Repeat-Measures Analysis in the Multi-Ethnic Study of Atherosclerosis (MESA). Epidemiology, 26, 310-320. http://dx.doi.org/10.1097/EDE.0000000000000267

[26] Hoffmann, B., Moebus, S., Dragano, N., Stang, A., Mohlenkamp, S., Schmermund, A., Memmesheimer, M., BrockerPreuss, M., Mann, K., Erbel, R. and Jockel, K.H. (2009) Chronic Residential Exposure to Particulate Matter Air Pollution and Systemic Inflammatory Markers. Environmental Health Perspectives, 117, 1302-1308. 
http://dx.doi.org/10.1289/ehp.0800362

[27] Adar, S.D., D’Souza, J., Mendelsohn-Victor, K., Jacobs Jr., D.R., Cushman, M., Sheppard, L., Thorne, P.S., Burke, G.L., Daviglus, M., Szpiro, A.A., Diez Roux, A.V., Kaufman, J.D. and Larson, T.V. (2015) Markers of Inflammation and Coagulation after Long-Term Exposure to Coarse Particulate Matter: A Cross-Sectional Analysis from the MultiEthnic Study of Atherosclerosis. Environmental Health Perspectives, in Press. http://dx.doi.org/10.1289/ehp.1308069

[28] van Eeden, S.F., Yeung, A., Quinlam, K. and Hogg, J.C. (2005) Systemic Response to Ambient Particulate Matter: Relevance to Chronic Obstructive Pulmonary Disease. Proceedings of the American Thoracic Society, 2, 61-67. http://dx.doi.org/10.1513/pats.200406-035MS

[29] van Eeden, S.F., Tan, W.C., Suwa, T., Mukae, H., Terashima, T., Fujii, T., Qui, D., Vincent, R. and Hogg, J.C. (2001) Cytokines Involved in the Systemic Inflammatory Response Induced by Exposure to Particulate Matter Air Pollutants (PM(10)). American Journal of Respiratory and Critical Care Medicine, 164, 826-830. http://dx.doi.org/10.1164/ajrccm.164.5.2010160

[30] Brito, J.M., Macchione, M., Yoshizaki, K., Toledo-Arruda, A.C., Saraiva-Romanholo, B.M., Andrade Mde, F., Mauad, T., Rivero, D.H. and Saldiva, P.H. (1985) Acute Cardiopulmonary Effects Induced by the Inhalation of Concentrated Ambient Particles during Seasonal Variation in the City of Sao Paulo. Journal of Applied Physiology, 117, 492-499.

[31] Clarke, R.W., Coull, B., Reinisch, U., Catalano, P., Killingsworth, C.R., Koutrakis, P., Kavouras, I., Murthy, G.G., Lawrence, J., Lovett, E., Wolfson, J.M., Verrier, R.L. and Godleski, J.J. (2000) Inhaled Concentrated Ambient Particles Are Associated with Hematologic and Bronchoalveolar Lavage Changes in Canines. Environmental Health Perspectives, 108, 1179-1187. http://dx.doi.org/10.1289/ehp.001081179

[32] Riediker, M., Cascio, W.E., Griggs, T.R., Herbst, M.C., Bromberg, P.A., Neas, L., Williams, R.W. and Devlin, R.B. (2004) Particulate Matter Exposure in Cars Is Associated with Cardiovascular Effects in Healthy Young Men. American Journal of Respiratory and Critical Care Medicine, 169, 934-940. http://dx.doi.org/10.1164/rccm.200310-1463OC

[33] Seaton, A., Soutar, A., Crawford, V., Elton, R., McNerlan, S., Cherrie, J., Watt, M., Agius, R. and Stout, R. (1999) Particulate Air Pollution and the Blood. Thorax, 54, 1027-1032. http://dx.doi.org/10.1136/thx.54.11.1027

[34] Vestbo, J., Hurd, S.S., Agusti, A.G., Jones, P.W., Vogelmeier, C., Anzueto, A., Barnes, P.J., Fabbri, L.M., Martinez, F.J., Nishimura, M., Stockley, R.A., Sin, D.D. and Rodriguez-Roisin, R. (2013) Global Strategy for the Diagnosis, Management, and Prevention of Chronic Obstructive Pulmonary Disease: GOLD Executive Summary. American Journal of Respiratory and Critical Care Medicine, 187, 347-365. http://dx.doi.org/10.1164/rccm.201204-0596PP

[35] Eisner, M.D., Anthonisen, N., Coultas, D., Kuenzli, N., Perez-Padilla, R., Postma, D., Romieu, I., Silverman, E.K., Balmes, J.R. (2010) Committee on Nonsmoking COPD, Environmental and Occupational Health Assembly. An Official American Thoracic Society Public Policy Statement: Novel Risk Factors and the Global Burden of Chronic Obstructive Pulmonary Disease. American Journal of Respiratory and Critical Care Medicine, 182, 693-718. http://dx.doi.org/10.1164/rccm.200811-1757ST

[36] Osman, L.M., Douglas, J.G., Garden, C., Reglitz, K., Lyon, J., Gordon, S., Ayres, J.G. (2007) Indoor Air Quality in Homes of Patients with Chronic Obstructive Pulmonary Disease. American Journal of Respiratory and Critical Care Medicine, 176, 465-472. http://dx.doi.org/10.1164/rccm.200605-5890C 